\title{
Angiogenic Marker Alterations Following Enamel Matrix Derivative Treatment: A Human Study
}

\author{
Onur Özçelik ${ }^{1}$, Gülşah Seydaoğlư ${ }^{2}$, Murat Cömert' ${ }^{3}$, Eftal Yılmaz ${ }^{3}$ M. Cenk Haytaç ${ }^{4}$ \\ ${ }^{1}$ Associate Professor, Çukurova University, Faculty of Dentistry, Department of Periodontology, Adana, Turkey \\ ${ }^{2}$ Associate Professor, Çukurova University, Faculty of Medicine, Department of Biostatistics, Adana, Turkey \\ 3 Research Assistant, Çukurova University, Faculty of Dentistry, Department of Periodontology, Adana, Turkey. \\ 4 Professor, Çukurova University, Faculty of Dentistry, Department of Periodontology, Adana, Turkey.
}

\section{Key Words}

Enamel matrix derivative, microvessel Density, vascular endothelial growth factor, angiogenesis, wound healing.

\footnotetext{
Correspondence:

Onur Özçelik,

Çukurova University,

Faculty of Dentistry,

Department of Periodontology,

Adana, Turkey.

e-mail: oozcelik@cu.edu.tr
}

\begin{abstract}
Aim: The aim of this immunohistochemical study was to assess the expression of angiogenic markers (vascular endothelial growth factor (VEGF) and microvessel density (MVD) in enamel matrix derivative (EMD) treated retromolar soft tissues to gain further insights into the biological mechanisms involved in wound healing and EMD treatment.
\end{abstract}

Methodology: In twenty healthy volunteers, gingival biopsies were obtained from the distal wedge operations of test (EMD-applied) and control sites. EMD was applied into the test sites during the operation. At the 15th post-operative day, the sample sites were reentered and gingival tissue samples were obtained from both test and control sites. A total of 80 samples for each sites were analyzed by immunohistochemistry for inflammatory infiltrate, expression of VEGF and MVD.

Results: Despite similar post-operative inflammatory infiltrate, it was found that EMD- applied sites had statistically higher VEGF-A and VEGF-C expression and MVD compared to the controls on the 15th day. ( $p<0.0001$ for each)

Conclusions: This study supports that EMD has an angiogenic potential. The findings of this immunohistochemical analysis may help to gain insight into the angiogenic effects of EMD during the early phases of wound healing.

(Int Dent Res 2012;2:8-16)

\section{I ntroduction}

In the last three decades, investigators have increased their efforts to seek for procedures and materials that promote periodontal regeneration and wound healing. Since it was shown that cellular growth and differentiation factors play a key role in wound healing, it has been suggested that such factors could enhance the regenerative potential of periodontal tissues (1-8). In this regard enamel matrix derivatives (EMD) have been widely investigated and are widely used. EMD is an extract of porcine embryonic enamel matrix. The enamel matrix is composed of a number of proteins, include $90 \%$ of which are amelogenins carried with a vehicle solution propylene glycol alginate abbreviated in PGA. EMD is thought to promote mesenchymal stem cells to mimic the processes that take place during the development of the nascent root and periodontal tissues (9-10). The principal role of EMD is to regulate biomineralization but growing evidence 
indicates that it also has the potential to act as a growth factor (11). The effects of EMD on host cells and extracellular matrix have been extensively studied in-vitro. These studies have shown that EMD selectively interact with different cell types during the wound healing process (e.g. keratinocytes, gingival and periodontal ligament fibroblasts, cementoblasts, osteoblasts)(7). These interactions can take place at the level of cellular attachment, mitogenesis, biosynthesis, and differentiation (11). However, most of these studies were performed in vitro or animal models and used outcome measures such as DNA synthesis, cell migration, cell proliferation, cell viability and expression of mediators involved in inflammation and wound healing $(6,7,12-21)$. Although it is shown that EMD can enhance the process of wound healing the mechanisms underlying this effect and that occur in vivo are not clear $(16,22-24)$. Wound healing is a complex and dynamic process that aims at restoring cells and tissues. It has been shown that angiogenesis is a key factor for proper wound healing. Vascular endothelial growth factors (VEGF) can be detected in vascular endothelial cells, inflammatory cells, junctional, sulcular, and gingival epithelium. They are a group of major angiogenic peptides which have specific mitogenic activities on vascular endothelial cells and are physiologically important for inflammation, and wound healing (25). In addition, another angiogenic molecule, CD34, which is a cell surface glucoprotein expressed by vascular endothelium and hematopoetic cells, is also considered to be an important marker for tissue vascularization and represents the microvessel density (MVD) in the tissue (26).

In periodontal tissues, angiogenesis seems to be important both for post-operative wound healing and maintenance of tissue health. Surprisingly, although it is known that EMD improves wound healing, its effect on angiogenesis as a key factor in this process is hardly investigated. The three available in vitro studies support the concept that EMD can stimulate angiogenesis directly (by stimulating endothelial cells and VEGF production) or indirectly (by stimulating the production of angiogenic factors by periodontal ligament (PDL) cells) (27-29). Although the data of these studies are consistent, to our knowledge, there is no evidence that EMD actually can influence VEGF production in vivo. Therefore, the aim of this study was to assess immunohistochemically whether EMD can influence angiogenesis during wound healing by altering the local MVD and VEGF levels.

The purpose of this immunohistochemical study was to assess the expression of VEGF and MVD in EMD treated retromolar soft tissues to gain further insights into the biological mechanisms involved in wound healing and EMD treatment.

\section{Materials and Methods}

\section{Power Analysis}

Sample size was calculated with an expected parameter estimate based on a similar study performed in our department (26). An assuming a mean of 18.5 MVD in control group and a mean of 30.9 MVD in EMD group with a 14.3 standard deviation, the minimum sample size thus required to be approximately 19 in each independent study groups and 12 in each dependent groups within a $90 \%$ confidence and $80 \%$ power.

\section{Study Population and Study Design}

20 periodontally healthy volunteers (11 females), aged between 24-32 years which were attending the Department of Periodontology, Faculty of Dentistry, Çukurova University between November 2009 and J anuary 2010 were included in this split-mouth prospective study. The patients were included if they had a bilateral congenital absence of mandibular third molars or when both mandibular molars were extracted at least two years ago (Figure 1A). Additionally the gingival thickness distally from the second mandibular molars had to be at least $4 \mathrm{~mm}$ (bone sounding with periodontal probe after local anesthesia) without any sign of inflammation. The clinical attachment level was $\leq 3$ $\mathrm{mm}$ in each site. Full-mouth plaque score and fullmouth bleeding on probing score was $<10 \%$. None of the second mandibular molars where restored with a prosthetic crown or any other type of restoration. Both the experimental and control sites had no history of mucogingival or periodontal surgery.

Exclusion criteria were: (1) not meeting the inclusion criteria, (2) diabetes, pregnancy, or any other systemic diseases known to affect periodontal tissues. (3) having received periodontal treatment 6 months prior to the study. The study was approved by the local ethical committee of the Cukurova University Faculty of Dentistry. All volunteers were thoroughly informed about the purpose of the study, the study set-up and the biological effects of EMD. A written informed consent was obtained from all volunteers before entering the study.

\section{Surgical Procedure and Gingival Biopsies}

Distal-wedge surgery procedures were performed at both mandibular retromolar sites in each subject (Fig. 1A). All surgical procedures were performed by the same periodontist $(\mathrm{OO})$. A priori, one retromolar site was randomly assigned for receiving EMD (test site) with a toss of a coin. The other site served as a control site. The distal wedge operations between test and control sites within 
each patient were performed on nearly 2-weeks intervals in order to prevent postoperative uncomfortable conditions. Surgical stents were prepared for both sites to standardize the biopsy area at baseline and the 15th day.

The distal wedge operation was performed under local anesthesia and the injection site was kept as distant as possible from the biopsy region to minimize any influence of injection on the tissue vasculature. Two parallel incisions, beginning at the distal portion of the second molar tooth and extending to the area with greatest amount of attached gingiva (distolingually or distofacially) were made with a 15C blade (Fig. 1B). A transversal incision was made at the distal end of the two parallel incisions. The rectangular piece of tissue in between the 3 incisions was removed and used as the baseline biopsy sample. In the test sites, the excised soft tissue area was carefully rinsed with saline, air-dried and was filled up with the EMD gel ${ }^{\circledR} \quad$ (Emdogain, Basel, Switzerland) (Fig. 1C). Approximately 0.2 cc of gel was inoculated in the test sites. The control sites were also rinsed, airdried and were filled up with nearly 0.2 cc of vehicle control (solvent, polyethylene glycol). 4-0 vicryl sutures were used to suture the buccal and lingual margins with an interrupted suture technique (Figure 1D). Approximately 0.1 cC of EMD gel and vehicle control was further introduced into the test and control sites after suturing. The periodontal dressing was applied to prevent EMD loss during immediate post-operative period. The dressing was also applied to the control operation area. The patients were advised not to eat or drink for at least two hours after the operation is completed. The postoperative care consisted of rinsing with $10 \mathrm{ml} \mathrm{a}$ $0.2 \%$ chlorhexidine solution twice a day for 2 weeks. Patients were requested to avoid brushing and chewing in the treated area for a period of two weeks.
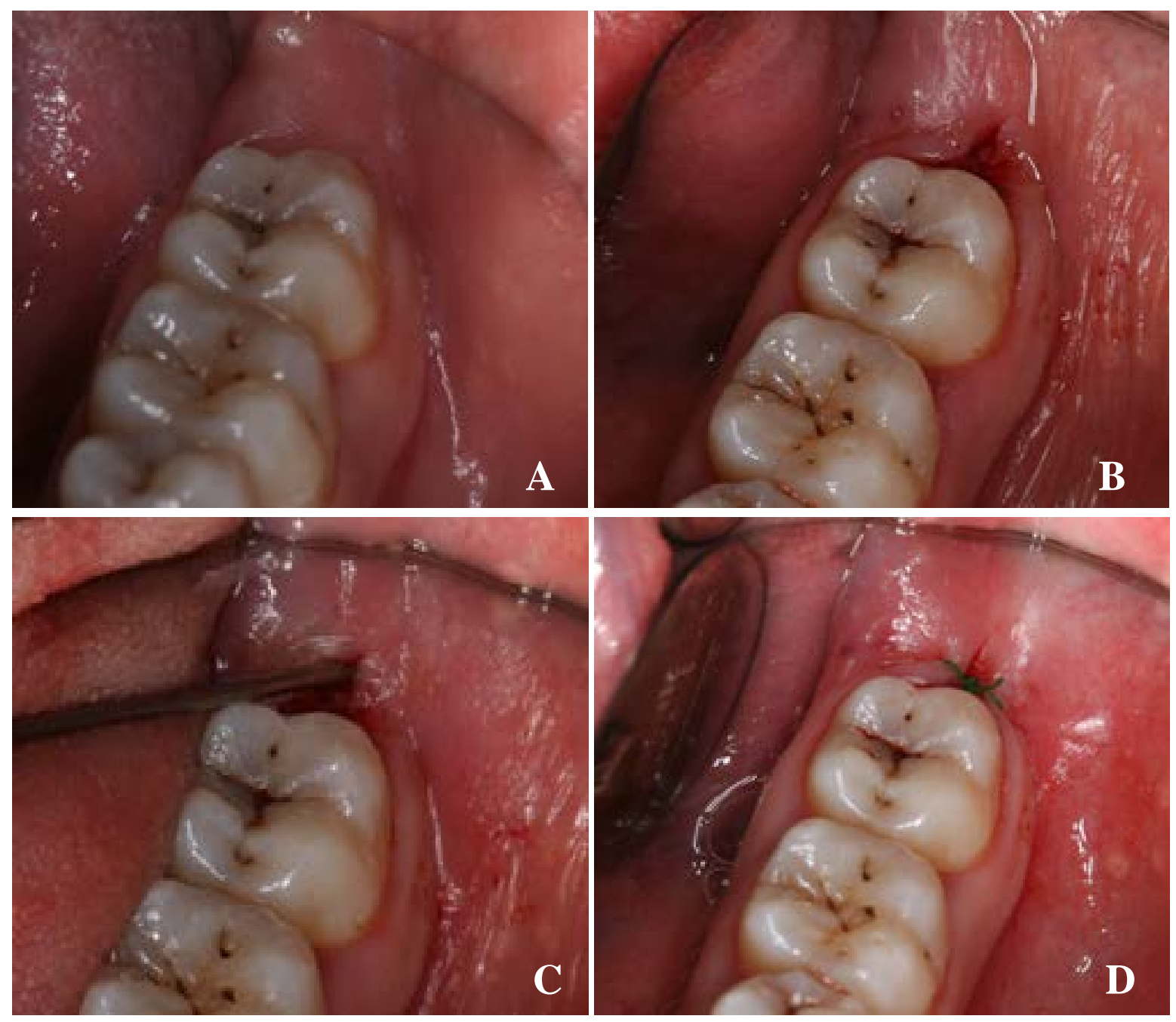

Figure 1: (A) Preoperative radiograph of the mandibular retromolar test site; (B) Intra-operative view of the wedge operation; (C) during EMD application; and (D) after suturing. 
The sutures and the dressing were removed 7 days following surgery. At the 15th post-operative day, the sample sites were re-entered and gingival tissue samples which was approximately $2 \times 2 \mathrm{~mm}$ were once again obtained from both test and control sites. The samples, which were embedded in a paraffin block, were immunohistochemically analyzed.

\section{I mmunohistochemistry}

Tissue samples of $2 \times 2 \mathrm{~mm}$ in size were washed with physiological saline and fixed in $10 \%$ neutral buffered formalin. From each biopsy sample, five sections, each 5-micron thick, were cut from the lamina propria of the formalin-fixed and paraffinembedded tissue samples. Additionally, they were dewaxed and

rehydrated. Endogenous peroxidase was blocked wi th $3 \%$ hydrogen peroxide. The sections were washed in $\mathrm{dH} 2 \mathrm{O}$. After washing with distilled water, antigen retrieval was done by medium powered microwave incubation in $10 \mathrm{mM}$ citrate buffer for 5 min. This process was repeated twice. Slides were then left to cool at room temperature. Sections were incubated with VEGF-A, VEGF-B and VEGF-C (Santa Cruz, CA, USA) and CD34 (Dako, Glostrup, Denmark) antibodies for 2 hours at room temperature. Subsequently they were washed with PBS and immersed with a biotinylated anti-I gG (antimouse and anti-rabbit IgG) for $30 \mathrm{~min}$. After washing with phosphate buffered saline (PBS), avidin-biotin horseradish peroxidase (ABC System, Vector Laboratories, Burlingame, CA, USA) (HRP) was applied for $45 \mathrm{~min}$. Slides were washed again with PBS. AEC chromogen (Santa Cruz, CA, USA) was used for color development. After washing with PBS, sections were counterstained with Mayer's hematoxylin. As a negative control for the primary antibodies, tissue sections were treated with nonimmunated rabbit and mouse serum instead of each primary antibody.

\section{Evaluation of VEGF Expression}

Immunostaining was evaluated independently by two pathologists who were blinded to the study groups. The evaluation method described by Aspriello et al. was used in this study. Briefly, by using a light microscope at $\times 25$ magnification, the number of VEGF-positive cells was counted among more than 1,000 cells in the more representative fields (30). The values obtained were expressed as a percentage of the total cells counted.

\section{Microvessel Density}

The sections were analyzed using the vascular hotspot technique to obtain MVD. Sections were scanned at low power to determine areas of highest vascular density. Within this region, individual microvessels were counted in three separate random fields at high power $(0.142-\mathrm{mm} 2$ field size). The mean vessel count from the three fields was used. A single countable microvessel was defined as any CD34+ endothelial cell or group of cells that was clearly separate from other vessels without the necessity of a vessel lumen or RBC (red blood cell) within the lumen. Each stained lumen was regarded as a single countable microvessel. Values were expressed as the number of vessels per square millimeter.

\section{Evaluation of I nflammation:}

An assessment of inflammation was determined by the density of the inflammatory cells (mainly lymphocytes, neutrophiles and plasma cells) on the whole slide with a light microscope at 40x semiquantitatively according to the criteria described by Mirbod et al. (31). Briefly, the categorization was as follows:

0 : no inflammatory cells in the tissue; 1 : Sparse distribution of inflammatory cells (up to $10 \%$ inflammatory cells per section) in 1 or 2 isolated sites; 2: Moderately dense accumulation of inflammatory cells (between $10 \%$ to $30 \%$ inflammatory cells per section); 3: Dense aggregation of inflammatory cells (more than 30\% inflammatory cells per section)

The calibration of the examiners was carried out by a previous examination of at least 20 sections at two different time intervals. Calibration was accepted if the results of these two examinations were similar at $90 \%$ level.

\section{Statistical Analysis}

Non-parametric tests were chosen for continuous variables since the data were not distributed normally. Comparisons between independent groups were done using the MannWhitney $U$ test and Wilcoxon rank test was used between dependent groups. Bonferroni's correction was applied $(p<0.10 / n$; where $n=$ number of comparisons) when multiple comparisons were made and a $p$ value $<0.025$ was considered as significant. Results were presented as mean \pm SD. Statistical analyses were performed using the statistical package SPSS v 15.0 (Chicago, Illinois).

\section{Results}

All patients completed the study course and complied with the post-operative recommendations. No post-operative complications such as swelling, bleeding or edema were observed in any patient and none of the patients used analgesics. The results of 
the immunohistochemical analysis of VEGF expression are summarized in Table 1 . There were no statistically significant differences of inflammatory infiltrate, VEGF-A, VEGF-B, VEGF-C expression and CD34+ cells between the EMDapplied and the control sites at the baseline. While the level of inflammatory infiltrate increased in both groups on the 15th day when compared to the baseline; there were no significant differences between test and control groups. When the VEGF levels at the 15th post-operative day were compared to the baseline within each group, it was observed that all VEGF subtypes significantly increased at the EMD-applied test sites ( $p<0.01$ for all) (Fig. 2) while VEGF-B was the only type, which had reached statistically significant difference $(p<0.05)$ in the control sites. The comparison of the VEGF levels of the test and control sites at the 15th day has shown that EMD- applied sites had significantly more expression of VEGF-A $(p<0.01)$ and VEGF-C $(p<0.05)$ and there were no differences for VEGF-B ( $p>0.05)$. In addition EMD-applied test sites had higher levels of CD 34+ cells (or MVD) on the 15th day when compared to the controls.

TABLE 1. Comparison of VEGF-A, -B, -C, MVD and inflammation on baseline and on the 15th day between control sites and EMD-applied sites

\begin{tabular}{|c|c|c|c|c|c|c|c|c|}
\hline & \multicolumn{2}{|c|}{$\begin{array}{l}\text { Control Group } \\
\text { (Mean } \pm \text { SD) }\end{array}$} & \multirow{2}{*}{$\begin{array}{l}\mathrm{p} \text { value } \\
\text { (Baseline vs } \\
15^{\text {th }} \text { day for } \\
\text { control) }\end{array}$} & \multicolumn{2}{|c|}{$\begin{array}{l}\text { EMD Group } \\
(\text { Mean } \pm S D)\end{array}$} & \multirow{2}{*}{$\begin{array}{l}\mathrm{p} \quad \text { value } \\
\text { (Baseline vs } \\
15^{\text {th }} \text { day for } \\
\text { EMD) }\end{array}$} & \multirow{2}{*}{$\begin{array}{l}\mathrm{p} \text { value } \\
\text { (Control } \\
\text { baseline vs } \\
\text { EMD } \\
\text { baseline) } \\
\end{array}$} & \multirow{2}{*}{$\begin{array}{l}\text { p value } \\
\text { (Control } \\
15^{\text {th }} \text { day vs } \\
\text { EMD } 15^{\text {th }} \\
\text { day) }\end{array}$} \\
\hline & Baseline & 15th day & & Baseline & $15^{\text {th }}$ day & & & \\
\hline VEGF-A (\%) & $14.3 \pm 4.1$ & $16.0 \pm 3.8$ & 0.035 & $13.5 \pm 4.0$ & $36.5 \pm 10.9$ & 0.0001 & 0.749 & 0.0001 \\
\hline VEGF-B (\%) & $12.8 \pm 3.4$ & $15.5 \pm 3.2$ & 0.001 & $13.5 \pm 4.3$ & $15.3 \pm 4.1$ & 0.038 & 0.475 & 0.038 \\
\hline VEGF-C (\%) & $13.3 \pm 3.7$ & $15.0 \pm 3.2$ & 0.053 & $13.0 \pm 3.8$ & $37.5 \pm 10.2$ & 0.0001 & 0.741 & 0.0001 \\
\hline MVD & $16.8 \pm 3.4$ & $17.8 \pm 2.6$ & 0.046 & $16.0 \pm 3.1$ & $47.5 \pm 11.2$ & 0.0001 & 0.454 & 0.0001 \\
\hline Inflammation & $0.9 \pm 0.6$ & $1.0 \pm 0.5$ & 0.705 & $0.9 \pm 0.4$ & $1.0 \pm 0.5$ & 0.480 & 1.000 & 0.739 \\
\hline
\end{tabular}

Significance level $\mathrm{p}<0.025$
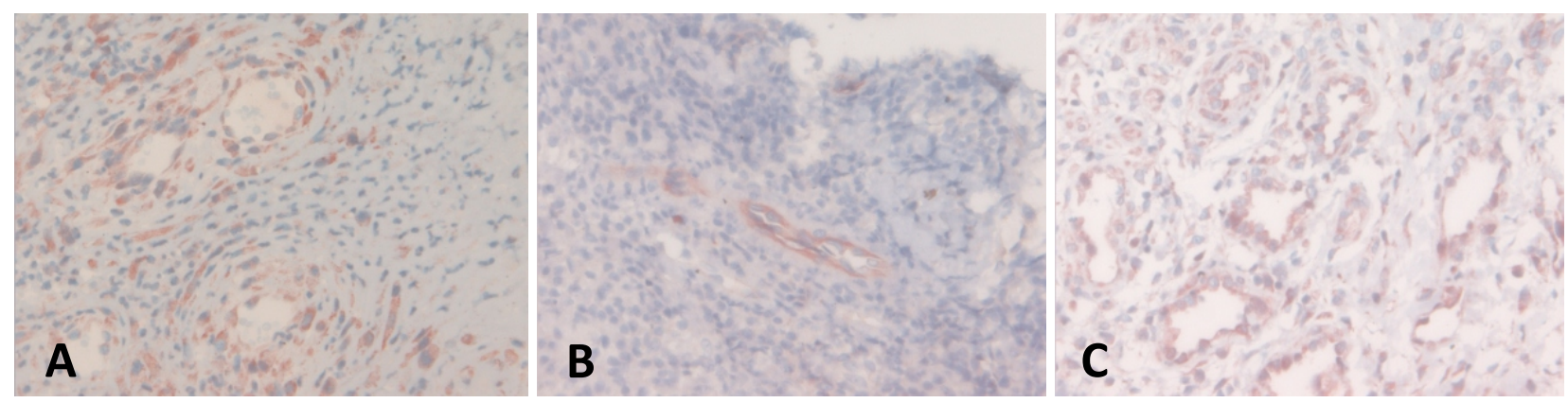

Figure 2: (A) Strong immunohistochemical staining for VEGF-A; (B) VEGF-B; and (C) VEGF-C at EMDtreated sites (x 400). 


\section{Discussion}

Among the factors influencing wound healing, angiogenesis (neovascularization) has been accepted as one of the important ones (32). The purpose of the present study was to gain insight into the angiogenic effects of EMD during the early phases of wound healing by immunohistological analysis of VEGF and MVD. Since it is well known that VEGF expression increases in both inflammation and wound healing, the inflammatory cell infiltration was also analyzed in order to distinguish if possible VEGF expression is related to vascular dilation or vascular proliferation. The results of the study have shown that, despite similar inflammatory cell infiltrate, EMD-applied sites had significantly higher VEGF expression and MVD. Although there are several studies, which analyze the angiogenic potential of EMD at the cellular and molecular levels, they were all in-vitro (27-29), gene array (33) and animal studies (27). To the best of our knowledge, this is the first human study to report the effects of EMD on angiogenic markers.

Numerous studies have been published to evaluate the biological mechanisms involved in EMD treatment $(3,6,7,21)$. However EMD-based angiogenesis stimulation is a quite new concept, which was first reported in 2003 (27). The in vivo angiogenic effects of EMD-soaked collagen membranes, which were implanted subcutaneously, were tested in a murine model. This study also investigated in vitro, the proliferation and chemotaxis of human umbilical vein endothelial cell (HUVEC). The data of the study showed that EMD application caused improved endothelial cell growth and increased the chemotactic effect on HUVECS compared to the control group. Additionally, new blood vessel outgrowths were also detected in the tissue culture of the EMD groups, but not in the control group. These results were recently supported by Johnson and coworkers which indicated that EMD-stimulated HUVECs showed a dose-dependent increase in proliferation (34).

Another in vitro study by Mirastschijski and coworkers (28) found that EMD-treated human dermal fibroblasts showed a five-fold increase in VEGF production compared to untreated control fibroblasts. In addition, a study by Schlueter and coworkers (29) reported that EMD stimulates angiogenesis directly by stimulating endothelial cells and indirectly by stimulating the production of angiogenic factors by PDL cells. It was demonstrated that the production of VEGF by PDL cells was increased four-fold when stimulated by EMD. These investigators also notified that EMD may enhance the communication between microvascular endothelial cells and PDL cells during angiogenesis associated with healing (29). These findings are consistent with a previous gene array study on human PDL cells which has shown that EMD had a stimulant effect on VEGF precursor gene regulation besides other genes encoding growth and repairpromoting molecules (33). The results of the present study are in accordance with all these concepts, which were reported in the aforementioned studies and indicate that EMD stimulates angiogenesis immunohistochemically in humans. The results are also consistent with the concept, that when used clinically, EMD stimulates angiogenesis, thereby accelerating the wound healing process by promoting the flow of nutrients and oxygen to the wound site.

Although the findings of previous studies and this study reported that EMD may have some angiogenic effects, the underlying molecules and mechanisms are not clear yet. The possible explanations can be discussed with the results of some previous studies. The first possibility may be the "the contamination" of angiogenic peptides during the process of obtaining EMD from porcines $(35,36)$. Recently, the contamination of bone sialoprotein (BSP)-like molecules in the commercial product of EMD has been detected (36) and interestingly, in a further study, BSP was shown to be capable of promoting angiogenesis through its cognate receptor, integrin avb3 BSP (37). Therefore, the existence of BSP-like protein could be partially responsible for the chemotactic effect of endothelial cells to the EMD product (27). Another possible explanation of indirect mechanism of promoting angiogenesis may be related with TGF- $\beta$ pathway, which has also been recognized as an angiogenic factor (38). Although TGF- $\beta$ contamination of EMD was not detected35, it was found that EMD can enhance the fibroblasts' expression of TGF- $\beta$ $(22,39)$. Additionally, it may have stimulatory effects on the periodontal ligament cells, which cause secretion of several growth factors, including TGF$\beta 1$, IL-6, and PDGF-A, -B) (27). The third probable pathway may be related to EMD-induced immune responses which may subsequently promote angiogenesis. Mild immune responses following EMD application in humans (40) and in animals (27) were demonstrated. It has been also reported that the expression of matrix metalloproteinase (MMP) of endothelial cells is upregulated during immunological reactions, and that the release of MMP promotes angiogenesis (41). The fourth and most plausible mechanism to promote angiogenesis may be the upregulation of the VEGF precursor gene by EMD, which has been proven by a gene array study (33). It was reported that the expression of VEGF or its precursors was directly upregulated by EMD in PDL cells. The over expression of this growth factor may stimulate the necessary cellular activities in vascular cells that lead to improved angiogenesis. Further in 
vivo studies analyzing the angiogenesis-related gene expression profiles in EMD-applied sites are needed to prove these concepts.

The angiogenic effects of the VEGF family are thought to be primarily mediated through VEGF-A $(25,26,42)$. When compared to the controls, the expression of VEGF-A was statistically significantly higher in EMD-treated sites. This finding is comparable to the previous studies (29). VEGF-B is the first member of the VEGF family that has a potent survival/anti-apoptotic effect, while lacking a general angiogenic activity. In a recent study, it was demonstrated that the major function of VEGF-B is to act as a "survival", rather than an "angiogenic" factor. In addition, VEGF-C is a molecular marker, which is involved in lymphangiogenesis $(43,44)$. In this study, both VEGF- B and VEGF-C expression levels were also found to be increased in EMDtreated sites (although not statistically significant for VEGF-B) when compared to the controls. In addition the amount of CD34 cells was significantly higher in EMD-treated patients compared with control. Currently, it is not possible to explain these findings clearly. Because new vessel formation is essential for wound healing, it is crucial to clarify the underlying mechanisms of stimulated-angiogenesis that lead to improved wound healing. Finding these underlying mechanisms, to explain these findings at molecular level, will be a challenge for the future.

\section{Conclusions}

In conclusion, the present study shows that EMD has strong stimulatory effects on VEGF expression and MVD during wound healing in human gingival tissues. The upregulation of these angiogenesis markers may suggest that the beneficial effects of EMD on the healing process are, at least in part, due to its stimulatory effects on neovascularization, which has been characterized as a key event in the induction of rapid wound healing.

\section{Acknowledgments}

The authors deny any conflicts of interest related to this study.

\section{References}

1. Pitaru S, McCulloch CA, Narayanan SA.Cellular origins and differentiation control mechanisms during periodontal development and wound healing. J Periodontal Res. 1994;29: 81-94.

2. Hammarstrom L. Enamel matrix, cementum development and regeneration. J Clin Periodontol. 1997;24: 658-68.

3. Heijl L. Periodontal regeneration with enamel matrix derivative in one human experimental defect. A case report. J Clin Periodontol. 1997;24: 693-6.

4. MacNeil RL, Somerman MJ. Development and regeneration of the periodontium: parallels and contrasts. Periodontol 2000. 1999; 19; 8-20.

5. Wikesjo UM, Selvig KA. Periodontal wound healing and regeneration. Periodontol 2000. 1999; 19: 21-39.

6. Sculean A, J unker R, Donos N, Windisch P, Brecx $M$, Dunker N. Immunohistochemical evaluation of matrix molecules associated with wound healing following treatment with an enamel matrix protein derivative in humans. Clin Oral Investig. 2003; 7: 167-174.

7. Venezia E, Goldstein M, Boyan BD, Schwartz Z The use of enamel matrix derivative in the treatment of periodontal defects: a literature review and meta-analysis. Crit Rev Oral Biol Med. 2004; 15: 382-402.

8. Ozcelik O, Haytac MC, Seydaoglu G. Immediate post-operative effects of different periodontal treatment modalities on oral health-related quality of life: a randomized clinical trial. J Clin Periodontol. 2007;34: 788-96.

9. Hammarstrom L, Heijl L, Gestrelius S. Periodontal regeneration in a buccal dehiscence model in monkeys after application of enamel matrix proteins. J Clin Periodontol. 1997; 24: 669-77.

10. Heijl L, Heden G, Svardstrom G, Ostgren A. Enamel matrix derivative (EMDOGAIN) in the treatment of intrabony periodontal defects. J Clin Periodontol. 1997;24: 705-14.

11. Kalpidis CD, Ruben MP. Treatment of intrabony periodontal defects with enamel matrix derivative: a literature review. J Periodontol. 2002; 73: 1360-76.

12. Begue-Kirn C, Krebsbach PH, Bartlett JD, Butler WT. Dentin sialoprotein, dentin phosphoprotein, enamelysin and ameloblastin: tooth-specific molecules that are distinctively expressed during murine dental differentiation. Eur J Oral Sci. 1998; 106: 963-70.

13. Fong CD, Cerny R, Hammarstrom L, Slaby I. Sequential expression of an amelin gene in mesenchymal and epithelial cells during odontogenesis in rats. Eur J Oral Sci. 1998;106 Suppl 1: 324-30.

14. Nanci A, Zalzal S, Lavoie P, Kunikata M, Chen W, Krebsbach PH, Yamada Y, Hammarstrom L, 
Simmer JP, Fincham AG, Snead ML, Smith CE. Comparative immunochemical analyses of the developmental expression and distribution of ameloblastin and amelogenin in rat incisors. J Histochem and Cytochem. 1998;46: 911-34.

15. MacDougall $M$, Simmons $D, G u ~ T T$, ForsmanSemb K, Mardh CK, Mesbah M, Forest $N$, Krebsbach PH, Yamada Y, Berdal A. Cloning, characterization and immunolocalization of human ameloblastin. Eur J Oral Sci. 2000;108: 303-10.

16. Hoang AM, Oates TW, Cochran DL. In vitro wound healing responses to enamel matrix derivative. J Periodontol. 2000; 71: 1270-7.

17. Trombelli L, Bottega S, Zucchelli G. Supracrestal soft tissue preservation with enamel matrix proteins in treatment of deep intrabony defects. J Clin Periodontol. 2002;29: 433-9.

18. Oida $\mathrm{S}$, Nagano $\mathrm{T}$, Yamakoshi $\mathrm{Y}$, Ando $\mathrm{H}$, Yamada $M$, Fukae $M$. Amelogenin gene expression in porcine odontoblasts. J Dent Res. 2002; 81: 103-8.

19. Papagerakis $P$, MacDougall M, Hotton D, BailleulForestier I, Oboeuf M., Berdal A. Expression of amelogenin in odontoblasts. Bone. 2003;32: 22840.

20. Le TQ, Zhang $Y$, Li W, Denbesten PK. The effect of LRAP on enamel organ epithelial cell differentiation. J Dent Res. 2007;86: 1095-9.

21. Bosshardt DD. Biological mediators and periodontal regeneration: a review of enamel matrix proteins at the cellular and molecular levels. J Clin Periodontol. 2008;35: 87-105.

22. Kawase T, Okuda K, Momose M, Kato Y, Yoshie $\mathrm{H}$, Burns DM. Enamel matrix derivative (EMDOGAIN) rapidly stimulates phosphorylation of the MAP kinase family and nuclear accumulation of smad 2 in both oral epithelial and fibroblastic human cells. J Periodontal Res. 2001; 36: 367-76.

23. Hagenaars S, Louwerse PH, Timmerman MF, Van d, V, Van der Weijden GA. Soft-tissue wound healing following periodontal surgery and Emdogain application. J Clin Periodontol 2004;31: 850-6.

24. Esposito M, Grusovin MG, Coulthard P, Worthington HV. Enamel matrix derivative (Emdogain) for periodontal tissue regeneration in intrabony defects. Cochrane Database Syst Rev. 2005.

25. Unlu F, Guneri PG, Hekimgil M, Yesilbek M, Boyacıoglu $H$. Expression of Vascular Endothelial Growth Factor in human periodontal tissues: Comparison of healthy and diabetic patients. J Periodontol. 2003; 74: 181-7.

26. Ozcelik O, Haytac MC, Ergin M, Antmen B, Seydaoglu G. The immunohistochemical analysis of vascular endothelial growth factors $A$ and $C$ and microvessel density in gingival tissues of systemic sclerosis patients: their possible effects on gingival inflammation. Oral Surg Oral Med Oral Pathol. 2008; 105: 481-5.
27. Yuan K, Chen CL, Lin MT. Enamel matrix derivative exhibits angiogenic effect in vitro and in a murine model. J Clin Periodontol 2003;30: 732-8.

28. Mirastschijski U, Konrad D, Lundberg E, Lyngstadaas SP, J orgensen LN, Agren MS. Effects of a topical enamel matrix derivative on skin wound healing. Wound Repair and Regen. 2004; 12: 100-8.

29. Schlueter SR, Carnes DL, Cochran DL. In vitro effects of enamel matrix derivative on microvascular cells. J Periodontol. 2007; 78: 14151.

30. Aspriello SD, Zzzzi A, Lucarini G, Rubini C, Faloia $E$, Boscaro $M$, Tirabassi $G$, Piemontese $M$. Vascular Endothelial Growth Factor and Microvessel Density in periodontitis patients with and without diabetes. J Periodontol. 2009; 80: 1783-9.

31. Mirbod SM, Ahing SI, Pruthi VK. Immunohistochemical study of vestibular gingival blood vessel density and internal circumference in smokers and non-smokers. J Periodontol. 2001; 72: 1318-23.

32. Tonnesen MG, Feng $X$, Clark RA. Angiogenesis in wound healing. J Investig Dermatol Symp Proc. 2000; 5: 40-6.

33. Schlueter SR, Carnes DL, Cochran DL. In vitro effects of enamel matrix derivative on microvascular cells. J Periodontol. 2007;78: 14151.

34. Parkar MH, Tonetti M. Gene expression profiles of periodontal ligament cells treated with enamel matrix proteins in vitro: analysis using CDNA arrays. J Periodontol. 2004; 75: 1539-46.

35. J ohnson DL, Carnes D, Steffensen B, Cochran DL. Cellular effects of enamel matrix derivative are associated with different molecular weight fractions following separation by size-exclusion chromatography. J Periodontol. 2009;80: 648-56.

36. Gestrelius $S$, Andersson C, Lidstrom D, Hammarstrom L, Somerman M. In vitro studies on periodontal ligament cells and enamel matrix derivative. J Clin Periodontol. 1997;24: 685-92.

37. Suzuki N, Ohyama M, Maeno M, Ito K, Otsuka K. Attachment of human periodontal ligament cells to enamel matrix-derived protein is mediated via interaction between BSP-like molecules and integrin alpha(v)beta3. J Periodontol. 2001;72: 1520-6.

38. Bellahcene A, Bonjean K, Fohr B, Fedarko NS, Robey FA, Young MF, Fisher LW, Castronovo V. Bone sialoprotein mediates human endothelial cell attachment and migration and promotes angiogenesis. Circ. Res. 2000; 86: 885-91.

39. Darland DC, D'Amore PA. TGF beta is required for the formation of capillary-like structures in threedimensional cocultures of 10T1/2 and endothelial cells. Angiogenesis. 2001;4: 11-20.

40. Van der Pauw MT, Van den Bos T, Everts V, Beertsen W. Enamel matrix-derived protein 
stimulates attachment of periodontal ligament fibroblasts and enhances alkaline phosphatase activity and transforming growth factor beta1 release of periodontal ligament and gingival fibroblasts. J Periodontol. 2000; 71: 31-43.

41. Petinaki E, Nikolopoulos S, Castanas E. Low stimulation of peripheral lymphocytes, following in vitro application of Emdogain. J Clin Periodontol. 1998; 25: 715-20.

42. Mach F, Schonbeck U, Fabunmi RP, Murphy C, Atkinson E, Bonnefoy JY, Graber P, Libby P. T lymphocytes induce endothelial cell matrix metalloproteinase expression by a CD40Ldependent mechanism: implications for tubule formation. AmJ Pathol. 1999; 154: 229-38.

43. Lucarini G, Zizzi A, Aspriello SD, Ferrante L, Tosco E, Lo ML, Foglini P, Mattioli-Belmonte M, Di $\mathrm{PR}$, Piemontese M. Involvement of vascular endothelial growth factor, CD44 and CD133 in periodontal disease and diabetes: an immunohistochemical study. J Clin Periodontol. 2009;36: 3-10.

44. Hicklin DJ, Ellis LM. Role of the vascular endothelial growth factor pathway in tumor growth and angiogenesis. J Clin Oncol. 2005;23: 1011-27. 